\title{
The Research on Vocational Skills Training for Chinese New Generation Migrant Workers in the Context of Balancing Urban and Rural Development
}

\author{
Jiabing Tian \\ School of Economics and Management \\ Southwest University \\ Chongqing, P.R. China \\ purebing@126.com
}

\author{
Linbo Zhou \\ School of Culture and Social Development \\ Southwest University \\ Chongqing, P.R. China \\ boboall@163.com
}

\begin{abstract}
- this paper tries to solve the problem of vocational skills training for Chinese migrant workers to promote the process of social integration and urbanization. From the perspective of balancing urban and rural development, the author has done some meaningful exploration with current literature and national policies. The conclusions are: the government has to make scientific training plans for new generation migrant workers; increase the government investment; promote the diversification of sources of investment; create good environment; set up long-term mechanism and provide full services. These conclusions could guide the work of Chinese new generation migrant workers from a brand new perspective.
\end{abstract}

Keywords-balance urban and rural development; new generation migrant workers; vocational skills; training

\section{INTRODUCTION}

After 30 years' reform and opening up, China's urban and rural economic development has experienced a great breakthrough. However, there is still a huge gap between the economic development of urban area and rural area. In October 2003, the Central Committee of the Communist Party of China clearly put forward the strategic thought_ " "balance urban and rural development". This strategic thought made the government start to focus on the comprehensive progress of the rural area. As a result, in order to speed up the process of urbanization of the migrant workers, the government has to further advance the urbanization construction through promoting the rural areas by urban areas, supporting the agriculture by industry, motivating urban-rural interaction and developing harmoniously (the research group of the State Council, 2006[1]). Yet currently, the migrant workers group in China is undergoing a great change. This not only embodies in these migrant workers' life style and work style - they shift from physical work to mental work; live from countryside to city; start a business in their hometown instead of only working in the cities, but also in the appearance of "new generation migrant workers". On February 1, 2010, the CPC (Communist Party of China) Central Committee and the State Council released its NO.1 document, entitled Proposals of the CPC Central Committee and the State Council on Strengthening the Efforts of Coordinative Urban-Rural Development and Further Consolidating the Basis of Agricultural and Rural Development. This document pointed out that the government should "strive to resolve the problems of new generation migrant workers", and it is the first time that the word "new generation migrant workers" appeared in the party's document, indicating that the Central Committee of the Communist Party cares much about the migrant workers born in 1980s or 1990s, and they accounts for about $60 \%$ of the total.

The new generation migrant workers' need for employment security is stronger than the first generation migrant workers. What's more, the first generation migrant workers' sense of identity on city is low and their attitude and idea are much closer to farmers; even when they cannot survive in the city, they can go back to farming, while the new generation migrant workers' sense of identity on city is relatively higher and their attitude and idea are much closer to the citizens. But compared with the urban labor, the new generation migrant workers lack necessary professional skills and the ability to enter into formal job market. Therefore, a huge gap between the new generation migrant workers' high expectations and the informal job market they face gradually comes into being. On one hand, these new generation migrant workers cannot really survive in the cities; on the other hand, they are not able to and not willing to go back to farming. As a result, they become the people who live at the verge of city and countryside (Mitchell, 1969[2]). From the perspective of balancing urban and rural development, the main tasks of governments at all levels to implement the vocational skills training project for new migrant workers are making training plans for them, increasing the government investment, contributing to the diversification of sources of investment, creating good environment, setting up long-term mechanism and providing full services. As for this, this paper has done some meaningful exploration.

\section{THE IMPORTANCE OF VOCATIONAL SKILLS TRAINING FOR NEW GENERATION MIGRANT WORKERS}

A. Vocational Sskills Training for New Generation Migrant Workers is the Objective Requirement of Harmonious Society Construction

At present, there are more than 200 million new generation migrant workers in China. Their average schooling years are short, and most of them haven't received systematic vocational skills training yet. In reality, they are doing the dirtiest, heaviest, hardest and the most dangerous job in the difficult and dangerous industry of the city. However, what they get is the lowest salary which can only maintain the labor reproduction. Furthermore, they have no basic social security and related benefits, and nearly no chance to integrate into the 
urban society. This situation is not only led by the household registration systems of urban and rural areas, but also caused by the short schooling years of the migrant workers and lacking of systematic vocational skills training. Because the human capital could create wealth and education is the key to form human capital (Wellman. B, 1988[3]). So we should recognize the vocational skills training for 200 million new generation migrant workers from the strategic height of building a harmonious society. Only after the migrant workers get the stepping stone (vocational skills education and the good mechanism) to realize their personal development in reality, can they promote their employment levels; gain the opportunity to get more income; improve their value of human capital; obtain social competitive power and gradually integrate into the urban society (Alejandro Portes, 1998[4]).

B. Vocational Skills Training for New Generation Migrant Workers Is a Important Way to Realize the Modernization of a Country

Compared with Japan's industrial workers' schooling years, China's new generation migrant workers who accounts for two-thirds of the industrial workers are educated 5-7 years less (Guo Ke, 2009[5]). Only one-tenth of the new generation migrant workers have received vocational skills training and this is far from meeting the demand of China's manufacturing industry which is heading to modernization for laborers' knowledge and skills. This embodies in China's lack of high-level professionals and skilled laborers. Even in Shanghai, whose equipment manufacturing industry is strong, there are only $6.2 \%$ senior skilled workers of all the skilled workers, which is far behind that of developed countries whose proportion of senior skilled workers is 30\%-40\% (Zheng Hang-sheng, 1996[6]). The low quality of laborers directly leads to China's extensive economy growth pattern which is characterized by high investment, high consumption and high pollution. Thus the improvements of labor productivity, the international competitiveness of products and the manufacturing industry of China have been influenced and restricted. Moreover, the process to realize industrialization and informatization has also been seriously restricted in China. In addition to popularization of high school education and cultivation of high skilled talents, the important way to improve the current situation is to popularize the vocational skills training for migrant workers.

\section{THE FUNCTION RECONSTRUCTION OF GOVERNMENT IN THE VOCATIONAL SKILLS TRAINING FOR NEW GENERATION MIGRANT WORKERS}

A. Make Scientific Plan and Overall Arrangement for Vocational Skills Training for New Generation Migrant Workers

First of all, practical vocational skills training plan for new generation migrant workers has to be made according to the strategy of modernization construction of China, directed by scientific outlook on development, combined with talent power strategy, requirement of cultivating high skilled talents and the actual status of migrant workers. Additionally, Decisions of the State Council on Further Strengthening the Rural Education Work and Proposals of the State Council on Solving the Problems of Migrant Workers could be the significant guiding principles to make this plan. Besides, the government should provide the new generation migrant workers with vocational skills training group by group in a balanced way, scientifically, orderly and efficiently. At the same time, the plan made by the Ministry of Agriculture entitled Training Plan for the National Migrant Workers in 2003-2010 and the Ministry of Education's plan to develop vocational education during the "eleventh five year plan" period lay a good beginning for the vocational skills training plan. In order to make this plan scientifically, the government has to make efforts to do research; fully encourage democracy and listen to all useful opinions. Additionally, the relevant departments under the state council should strengthen the leadership; governments at all levels should help to create good social atmosphere and policy environment step by step, and various nongovernmental forces should be encouraged to do vocational skills training for migrant workers, promoting the migrant workers' transformation from physical type to skilled and intellectual type.

\section{B. The Government Increases the Investments to Promote the Diversification of Investors}

Research shows that, the investment profit coming from human resources is 3-5 times more than the investment cost coming from human resources. Firstly, governments at all levels must pay enough attention to the vocational skills training for migrant workers from the strategic height; continue to increase the investment on the basis of increased investment; establish standard transfer payment system of migrant workers training funds and further enrich the county financial resources, realizing the unity of the rights of human, finance and affairs. Secondly, the governments have to attract more investments no matter they are domestic or foreign to promote the diversification of investors of vocational skills training for migrant workers (He Zhai-ping, 2001[7]). Lastly, the central government should support the local government; all kinds of enterprises and private institutions should be encouraged to invest in the vocational skills training for migrant workers and the governments could attract international organizations, entrepreneurs and overseas Chinese to come to China to train the migrant workers with preferential policies. In addition, the big cities in China should better actively train the migrant workers who work there. Meanwhile, the foreign companies also have to undertake the social responsibilities in China. That is to say, they should also invest to train the migrant workers instead of enjoying the ready-made human capital and human resources. Therefore, the government could use the sufficient funds financed by diversified investors to start the vocational skills training project for migrant workers.

C. Create Good Environment for Vocational Skills Training for New Generation Migrant Workers, Promoting Their Integration into Cities

First of all, in the process of diversifying the investors of vocational skills training for migrant workers, the governments should switch its function and role in time, changing from the organizers of the education market to managers or servers. Furthermore, the governments have to create fair policy and legal environment, impartial market competition environment as well as good employing environment for investors according to related laws and regulations. Meanwhile, they should make market rules according to laws; standardize the behavior of 
investors and operators; supervise their education quality, service quality and professional reputation; protect the rights and interests of the migrant workers participating in training. Then, in order to establish good mechanism for migrant workers to transfer to the secondary industry and tertiary industry as well as integrate into urban society, the governments have to promote the abolition of household registration system of urban and rural areas, treating the farmers as the urban residents. As for employment and school policy, employing system, salary and social security, farmers and urban residents should also be treated the same. In addition, the governments should cancel all kinds of discriminations and restrictions on migrant workers, providing relevant information for them in time (Zhao Fang, 2003[8]).

D. The Government Improves the Social Management Function and Provides Full-service for the Employment of New Generation Migrant Workers

Firstly, the government could provide information service. On one hand, they could provide migrant workers with legal policy advice, employment information, employment guidance and employment service. On the other hand, they can provide the number, type, skills and professional information of migrant workers needed in each city or town as well as the vocational skills training institutions together with its qualifications and credit information for the migrant workers. Thus the migrant workers can participate in the vocational skills training purposely, selectively and specifically, working in the company that is in need successfully.

Secondly, hardware service facilities for vocational skills training for migrant workers should be constructed and services connected with socialization, publicity and network should also be implemented. This public service project cannot be done by an individual person or enterprise. Only with the necessary funds invested by government and the development and training of social forces, could this project be done.

Lastly, the migrant workers talent market should be developed. The spontaneously disordered market formed by the migrant workers does exist. In addition to it, the governments have to develop a free regional migrant workers talent market service system with thorough functions, sound mechanism, relevant regulations, timely guidance, considerate service, overall planning and key deployment gradually and selectively. Finally, the migrant workers talent market service system has to play a role in attracting needed migrant workers for companies and revitalizing the economy.

\section{THE INNOVATIVE WAY OF VOCATIONAL SKILLS TRAINING FOR NEW GENERATION MIGRANT WORKERS}

\section{A. Actively Bring the NGO (non-government organization) into Play and Improve the training quality}

As a matter of fact, the new generation migrant workers' demand for vocational skills training is very strong, but they cannot afford the expensive training expenses of the for-profit training institutions. Additionally, the quality of designated training is low, thus the market competition mechanism should be introduced in the vocational skills training for migrant workers. Therefore, the government should better resolutely put an end to the designated training and issue the training subsidies not in cash, inspiring the enthusiasm of training institutions and migrant workers participating in training greatly. The government would better spare no effort to form a pattern that the governments pay for the training expenses; the training institutions compete freely with each other and the migrant workers select training institution and training content independently. In reality, the government could issue training tickets to the migrant workers and the training organizations which are already approved by labor and social security departments arrange the training according to the defined training content. The migrant workers with training tickets cannot be asked to pay in cash. Instead, the designated institution of the government is responsible for accounting and paying for the training fees if the migrant workers who have been trained are proved to be qualified. Consequently, a pattern that training and acceptance is separated comes into being (Wang Chun-guang, 2000[9]).

\section{B. Reform the Training Content; Emphasize on Practicality} and Applicability

According to the current integration trend of social production, science and technology as well as education, it is necessary for the migrant workers to take courses that could teach them how to survive and develop in cities and promote their qualities. Additionally, the training for them should give priority to practical science and technology knowledge, operation skills and service skills, so that the migrant workers could apply what they have learned into practical use. Besides, on the basis of training of professional skills and practical skills, the training organizations can carry out some other training courses like basic rights and interests, legal knowledge, common sense of city life and skills to look for jobs. In this way, the consciousness of migrant workers to comply with laws and regulations, protect their own rights and interests could be greatly improved. With the improvement of competitiveness, the migrant workers may set up new employment concept.

C. Create a New Mode of Vocational Skills Training for New Generation Migrant Workers

The local government issues training tickets to the migrant workers according to the actual number of them. Migrant workers with training tickets could either be trained in their birth place, or in the cities where they are working in. In the cities, the migrant workers are trained in the training institutions with market competition mechanism or in the institutions of some certain companies that are doing service for the society. Such kind of training institutions cannot collect training tickets or cash. Moreover, the migrant workers could select the training institutions, training level and training content independently. Each training institution can introduce a new mode of training, which is migrant workers employment training mode with integration of training, employment and rights protection. In addition, it is characterized by "state-owned, privately-run" (Wang Chun-guang, 2002[10]). "Privately-run" refers to that the training school is society-oriented with joint stock and limited liability founded by non state financial education funds. As for property rights and management system, there is a distinguished difference between public vocational skills training schools and private ones. "State-owned" refers to that the schools could get the help of government (Poverty Relief Office) when they are 
recruiting new students, and gain the support of government (Community Service Center affiliated to Civil affairs bureau) in the aspect of employment. Such kind of training mode that the schools cooperate with the governments in the link of recruitment and cooperate with the government in the link of employment is a kind of innovation currently, and it is worthy to be the references and popularized.

\section{CONCLUSIONS}

This paper has put forward that the government need function reconstruction in the training for new generation migrant workers, including scientific planning, diversified investment, full service and establishment of mechanism of migrant workers' integration into cities. This shows that the innovative ways of vocational skills training for new generation migrant workers are giving priority to $\mathrm{NGO}$ and private institutions, innovating training mode, reforming training content and the use of market orientation.

At present, most of the new generation migrant workers are doing casual work, temporary work and part-time job. Under the severe employment situation, the government should play the roles of public administration and social management; continuously improve their working skills; provide them with more vocational education and training; give them as many development opportunities as possible and expand their employment social support network. This is of great social meaning and realistic meaning.

\section{ACKNOWLEDGMENT}

Financed by Humanities and Social Science Fund of the Ministry of Education (West Project): Construction and
Integration: Research on New Generation Migrant Workers' Social Support Network under the Background of Coordinating Urban and Rural Areas (Project No.: 10XJC840003);Financed by National Social Science Fund: Research on New Generation Migrant Workers' Social Support Network(Project No.: 11CSH006)).

\section{REFERENCES}

[1] The Research Group of the State Council. Survey Report on Chinese Migrant Workers [R]. Beijing: Chinese Yanshi Press, 2006: 3-4.

[2] Mitchell. The Concept of Labor and Society [M]. University of Manchester press, 1969: 46-47.

[3] Wellman. B. Structural Analysis: From Method and Metaphor to Theory and Substance [M]. Cambridge University Press, 1988: 102-104.

[4] Alejandro Portes. Social Capital: Its Origins and Applications in Modem Sociology [J]. Annual Review of Sociology, 1998 (24): 1-24.

[5] Guo Ke. Integration and Conflict - Social Identity of the New Generation Migrant Workers [D]. Master's Degree Thesis, Northwest University, 2009 (4): 34-35.

[6] Zheng Hang-sheng. The Transforming Chinese Society and Transformation of Chinese Society [M]. Beijing: The Capital Normal University Press, 1996: 10-12.

[7] He Zhai-ping. Research Summary on Foreign Social Support Network [J]. Foreign Social Science, 2001 (1): 120-123.

[8] Zhao Fang. New Generation: A Concept Difficult to Define [J]. Sociology Research, 2003 (6): 75-77.

[9] Wang Chun-guang. New Generation Floating Population's Desire for Citizenship [J]. Democracy and Science, 2000 (1): 94-97.

[10] Wang Chun-guang. The Motivation to Go Out and Action Selection of the New Generation Floating Population $[\mathrm{J}]$. Chinese Cadres Tribune, 2002 (7): 33-34. 